\title{
Application of the Health Belief Model to HIV Testing and Counselling Among Youth Living in Selected Rural Communities in Ghana
}

\author{
Kennedy Nyeseh Ofori \\ Department of Education Studies, Wesley College of Education, Kumasi, Ghana
}

\section{Email address:}

kennyofori@yahoo.com

\section{To cite this article:}

Kennedy Nyeseh Ofori. Application of the Health Belief Model to HIV Testing and Counselling Among Youth Living in Selected Rural Communities in Ghana. International Journal of HIV/AIDS Prevention, Education and Behavioural Science.

Vol. 5, No. 1, 2019, pp. 11-18. doi: 10.11648/j.ijhpebs.20190501.12

Received: December 14, 2018; Accepted: January 5, 2019; Published: January 29, 2019

\begin{abstract}
Human Immune Virus/Acquired Humane Deficiency Syndrome (HIV/AIDS) is a pandemic that has caused devastating effects on both infected and affected persons. However, with the discovery of Anti-Retroviral Therapy, early detection of HIV leads to timely treatment, which significantly leads to prolong life. This study aimed at predicting the HIV Testing and Counselling (HTC) behaviour of youth of selected rural communities in Ghana using the health belief model (HBM). This cross sectional study was conducted on 424 youth using a questionnaire. By applying the multi stage sampling technique, a dominantly rural district was first purposefully selected, and then the communities through simple random sampling, and lastly the individual youth were purposefully selected. Data was processed and analysed using SPSS version 22 software. Findings from the study revealed that, respondents' perceived susceptibility to HTC, perceived benefits and the level of awareness (cues to action) were high, however respondents perceived barriers to HTC was indifferent. It was also found that an increase in a person's perceived benefits was likely to affect one's perceived barriers to participate in HIV Testing and Counselling. This indicates a crucial need for formal educational programs to sensitize them regarding the benefits of HTC. Stakeholders in health should therefore focus HIV/AIDS educational programmes on the benefits of HIV screening behaviours to the youth.
\end{abstract}

Keywords: Health Belief Model, HIV/AIDS, HIV Testing and Counselling, Youth, Utilization

\section{Introduction}

Over three decades ago since Human Immune Virus (HIV) was identified, all attempts to get a lasting cure or vaccine for this dreadful disease has been unsuccessful [1]. According to UNAIDS fact sheet report of 2017, about 36.9 million people globally were living with HIV while sub-Saharan African alone accounts for 66.7 per cent [2]. Statistics in Ghana also shows that for 2017 an estimate of 261,770 persons are living with HIV/AIDS. The report further indicates that in just that year 15,116 people died of AIDS related illness while new HIV infections in Ghana have recorded an alarming 70.15 per cent increase. Similarly, youth within the ages of 15-24 years account for 25 per cent of new infections [3, 4]. Therefore, HIV/AIDS is considered a major concern throughout the world including Ghana [5]. The Sustainable development goal has one of its target of ending the HIV and AIDS pandemic by the year 2030 [6]. As such, the key in ending this devastating pandemic is early diagnosis of the virus, which with treatment of Antiretroviral Therapy (ART) will reduce the mortality rate of persons living with HIV/AIDS [7]. Thus, participation of youth in early diagnosis and screening programme is very paramount. However, it seems that HIV Testing and Counselling (HTC) utilization among youth is very low and only a few of them undertake HTC.

For instance, studies conducted in Ghana reveal that only 25 per cent had utilized HTC [7, 8]. Early diagnosis of youth with HIV/AIDS can take place only with participation in HTC, which is affected by factors such as fear for HIV test, lack of trust for health personnel (confidentiality), unavailability of ART, stigmatization, inadequate HTC centres, cultural sensitivity and religious believes $[9,10]$. In 
Ghana, due to these different factors that affect the utilization of HTC and also the slowdown in HIV educational programmes and campaigns, HTC takes place at very low rate [11]. Therefore, it is important to pay attention to this menace in order to promote HTC via model of changing behaviour [12].

One model of importance that has proven to predict health behaviour among people is the Health Belief Model (HBM), developed by Hochbaum and Rosenstock in the 1950s [13, 14]. HMB originally had perceived susceptibility, perceived severity, perceived barriers, perceived benefits and cues to action as its constructs; later self-efficacy was added. According to HBM, when individuals see themselves as vulnerable or at risk to a particular health condition (perceived susceptibility), he/she should realize the seriousness or consequence of the disease (perceived severity), believe in the positive outcome when a preventive action is taken (perceived benefits) and that the benefits are greater than the barriers associated (perceived barriers), also there are activities or events that motivates individuals' preventive behaviour (cues to action) coupled with selfconfidence to carry the desired behaviour (Self-efficiency), that is, the belief in oneself to master courage to execute the required behaviour will ultimate aid the individual exhibit the required behavioural change $[15,16]$.

Several studies have been carried out on deferent prevention methods of HIV/AIDS such as use of condom, Prevention of Mother to Child Transmission (PMTCT), and so on using HBM $[17,18,19]$. However, few studies have been done regarding predictive constructs of HBM in adopting HTC among youth. For example, in a study to examine the perception and attitude of students regarding HTC services in the context of the HBM, less than 50 per cent of the participants perceived themselves to be susceptible to HIV infection. With regards to perceived severity and perceived benefits, half of the participants had high perception towards the seriousness of HIV/AIDS, while one forth $(25 \%)$ of them attested to the benefits of HTC services as an effective preventive measure against HIV/AIDS [20]. The study is significant to the present study as it employed a similar quantitative method among youths using the same HBM. Perhaps, the application of HBM in HTC is essential in order to understand sexual health psychology of the youth.

Similarly, another study among the youth of Hawassa town sought to determine the factors influencing utilization of HTC service among youth aged 18 to 24 years. It was a cross sectional qualitative study conducted through the application of HBM. Only a few perceived HTC to be beneficial. Participants perceived barriers such as fear of stigma and discrimination, inability to cope with positive test results were main hindrance to HTC [21]. The study is relevant to the present study as the author explores HTC in the light of the HBM. Respondents of the current study were individuals who were within the youthful ages of 15-24 years similar to the participants that were sampled for the present study. The only difference was that the study employed a qualitative method as against a quantitative method that was employed in the present study. Therefore, these differences in findings from the earlier studies demand further research on this menace. It is believed that the findings will increase knowledge on issues pertaining to youth participating in HTC. The findings will also serve as a guide for health practitioners, stakeholders and policy makers on strategies to adopt to get more youth to know their status in order to curb this devastating disease.

\section{Conceptual Framework}

The conceptual framework was guided by the Health Belief Model (HBM). This type of psychological model is used in predicting whether a person will perform an activity necessary for preventing a disease or not, depending on the belief or perception of the person about the seriousness of the disease, the merits and demerits of the prevention activity and their own ability to perform the activity [22]. The person's perceived susceptibility to the disease, perceived severity of the disease, perceived benefits of the preventive action, perceived barriers against the preventive action, certain cues to perform the preventive action and the person's self-efficacy all interact within the person to determine the person's readiness to perform the preventive action $[23,24$, 25].

In applying the HBM to HIV/AIDS prevention, DowningMatibag \& Geisinger studied casual sexual activity among college students and verified the validity of the HBM. They concluded that, there is high likelihood that people will perform an HIV/AIDS prevention activity such as wearing condom correctly and consistently for sexual intercourse or undertake HTC, if they believe that HIV/AIDS is a severe disease condition and they are highly susceptible to it [21]. In addition they must have the belief that the activity they need to perform to prevent HIV/AIDS, in this instance, going for HTC is highly beneficial and there are no barriers such as accessibility, availability, affordability and confidentiality issues. Furthermore, they need high degree of self-efficacy, that is, they must have high level of confidence in their own ability to perform that activity for preventing HIV/AIDS. This should also be supported with frequent encouragement to go for HTC, that is, cues to action. The cumulative effects of all these favorable factors make people take preventive action [23]. On the other hand, perception of being nonsusceptible to HIV/AIDS, no severity of HIV/AIDS, little or benefits of the preventive action such as HIV testing, with many barriers against its use as well as no absence of cues to action and self-efficacy or self-confidence will lead to failure of people to perform the actions needed to prevent HIV/AIDs [21]. In addition certain modifying factors such as the level of education, gender, ethnicity, marital status, just to mention a few can have effect on a person's behaviour and decision to perform the desired prevention activities. 


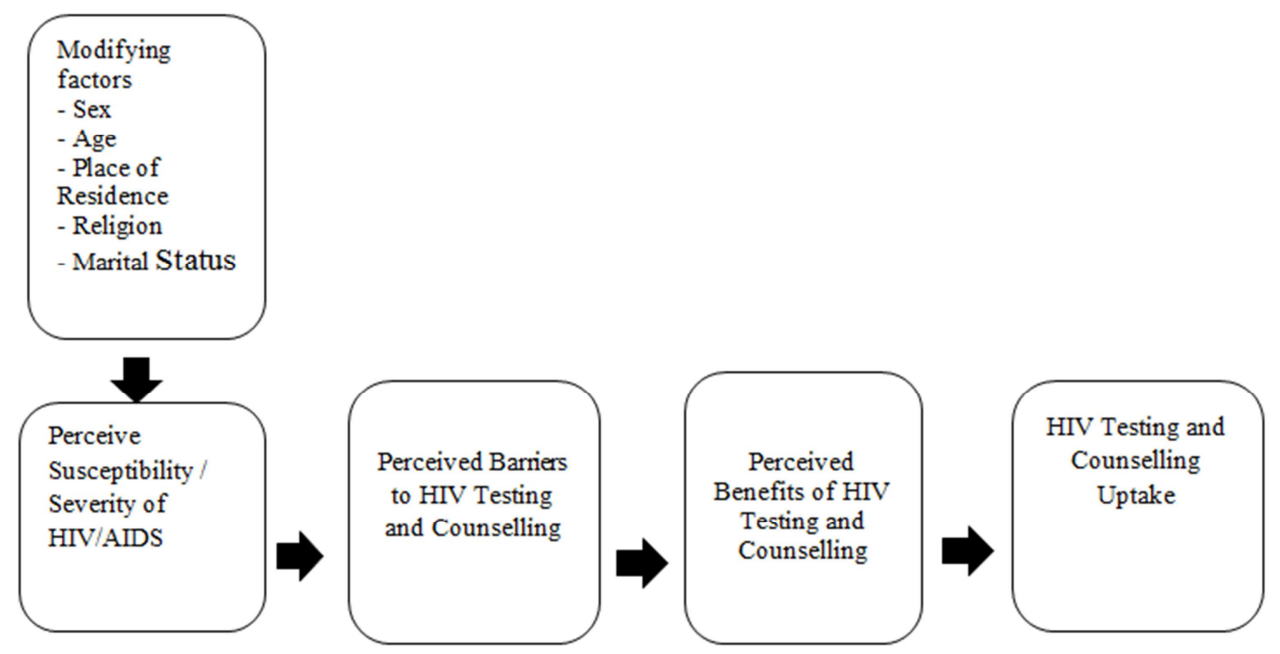

Figure 1. Conceptual framework of the Health Belief Model (Developed by Author).

\section{Methods and Materials}

\subsection{Study Design}

A research design is defined as the basic plan used as a guide for the process of collection data from participants and analyzing [26]. This definition gives an ontological understanding regarding the choice of cross-sectional survey design as an appropriate design for the study among rural youths. Cross sectional research designs are snapshot descriptive studies of a situation at one particular time [7].

\subsection{Study Area}

The study was carried out between June, 2017 and October, 2017 in Fanteakwa district in Ghana which is largely rural (About 70\%). The choice of Fanteakwa district was also because it is currently the rural site with the highest HIV prevalent rate in Ghana (that is; $4.2 \%$ ). The main occupation of the people in this area is dominantly farming, followed by petty trading, whilst the remaining occupations are public service workers and artisans [27].

\subsection{Study Population Selection Criteria}

The population for the study consisted of all youth between the ages of 15-24 years within the two Fanteakwa Districts of the Eastern region of Ghana. The total number of youth between the ages 15-24 in the districts was 18,060 [27]. Additionally, to be eligible to participate in the study, an individual should have lived in the study areas for not less than one year and freely give his/her consent to partake in the study.

\subsection{Sample Size and Sampling Technique}

The sample size was determined using the formula:

$$
n=\frac{N}{1+N(\propto)^{2}}
$$

Where $=\mathrm{n}$ is the sample size, $\mathrm{N}$ is the total number of target population and $\alpha$ is the margin of error $(5 \%)$. Therefore, the sample size determined was 424 . The multistage sampling size was employed to for the study. Firstly, the district was selected through the purposive technique. Then, the communities were selected through the simple random sampling and finally the individual youth in the household were purposively selected since not everyone was qualified to be selected for the study (only those between 1524 years). The sample size was distributed proportionally to each district based on the number of youth present. Two hundred and seven 207(48.8) of the respondents were males and two hundred and seventeen $217(51.2 \%)$ were females. The age range of the respondents was $15-19$ years $(64.2 \%)$ and $20-24$ years $(35.8 \%)$.

\subsection{Data Collection}

The relevant data for the study was obtained using a questionnaire designed by the researcher. The 30 item questionnaire which had questions on the socio-demographic data of respondents, HTC, perceived susceptibility, perceived benefits, perceived barrier sand cues to action was initially prepared in English Language and subsequently translated into the local language, Akwapem-Twi. The researcher recruited and trained five data collection assistants to help facilitate the data collection. A pre-test was first carried out at Apedwa, a rural community within the Abuakwa South Municipality of the Eastern Region of Ghana, (which has similar characteristics with that of the study area), to assess the reliability of the instrument. The validity of the research instrument was determined through peer review process. The pre-test was to ensure that the instrument was reliable, unambiguous, adequate and suitable for the study. After processing the pre-test results using cronbach alpha, reliability co-efficient of 0.79 was obtained, making the instrument highly reliable.

\subsection{Data Analysis}

The data collected was cleaned, coded and processed using 
Statistical Package for Social Science (SPSS) version 22.0 software. The results were represented in the form of frequencies, percentages and means. The bivariate relationship was determined between the demographic characteristics of respondents and the construct of the health belief model.

\subsection{Ethical Considerations}

Ethical approval was given by the Ethics Committee for Humanities of the University of Ghana. Written informed consent of all respondents were obtained from respondents who were above 18 years, while the respondents who were below 18 years were made to attest to the child assent form and written consent of their parents or guardians was also obtained. The data collectors ensured the anonymity of the respondents, respect for voluntary participation and confidentiality of information.

\section{Results}

The objective of the study was to determine how the constructs of the HBM (perceived susceptibility, perceived barriers, perceived benefits and cues to action) relate to HTC participation. Thus, the results from respondents on perceived susceptibility of HTC is presented on Table 1.

Table 1. Perceived Susceptibility.

\begin{tabular}{|c|c|c|c|c|}
\hline Variable & Freq & Percentage & $\overline{\mathbf{x}}$ & SD \\
\hline \multicolumn{5}{|c|}{ Chances of people in locality getting HIV } \\
\hline Strongly Agree & 115 & 27.1 & 4.41 & 1.26 \\
\hline Agree & 149 & 35.1 & & \\
\hline Disagree & 78 & 11.3 & & \\
\hline Strongly Disagree & 40 & 9.4 & & \\
\hline \multicolumn{5}{|c|}{ High chances of person getting HIV infected } \\
\hline Agree & 94 & 22.2 & & \\
\hline Don't Know & 53 & 12.5 & & \\
\hline Disagree & 115 & 27.1 & & \\
\hline Strongly Disagree & 93 & 21.7 & & \\
\hline \multicolumn{5}{|c|}{ Worried about getting HIV } \\
\hline Strongly Agree & 81 & 19.1 & 3.64 & 1.44 \\
\hline Agree & 84 & 19.8 & & \\
\hline Don't Know & 43 & 10.1 & & \\
\hline Strongly Disagree & 89 & 21 & & \\
\hline
\end{tabular}

$\overline{\mathrm{x}}=$ mean, $\mathrm{SD}=$ Standard Deviation.

Table 1; represents the analysis of the responses regarding respondent's perceived susceptibility to HTC. The majority of the respondents showing $62.2 \%$, with a mean of $(\overline{\mathrm{x}} 4.41 \mathrm{SD}=$ 1.26) shows that the chances of community members being infected with HIV is high. Similar results were received on individuals getting the virus as high $(\overline{\mathrm{x}}=4.04 \mathrm{SD} 1.96)$. The level of acceptance as to whether the respondents were worried about getting HIV was moderately high $(\overline{\mathrm{x}}=3.64 ; \mathrm{SD}=1.44)$. The standard deviation showed that the individual responses were clustered around the mean. Again from the table, the general mean of the respondent's perceived susceptibility to HTC was determined to be high (general mean=4.03). This is an indication that majority of the respondents perceived themselves to be susceptible to HIV test. On perceived benefits, the results in Table 2, provided what the respondents thought.

Table 2. Perceived Benefits.

\begin{tabular}{|c|c|c|c|c|}
\hline Variable & Freq & Percentage & $\overline{\mathbf{x}}$ & SD \\
\hline \multicolumn{5}{|c|}{ Using HTC likely to lower HIV infection } \\
\hline Strongly Agree & 118 & 27.8 & 3.39 & 1.09 \\
\hline Agree & 203 & 47.9 & & \\
\hline Don't Know & 43 & 10.1 & & \\
\hline Disagree & 30 & 7.1 & & \\
\hline Strongly Disagree & 28 & 6.6 & & \\
\hline \multicolumn{5}{|c|}{ Knowing HIV status to reduce transmission } \\
\hline Agree & 160 & 37.7 & & \\
\hline Don't Know & 50 & 11.8 & & \\
\hline Disagree & 74 & 17.5 & & \\
\hline Strongly Disagree & 24 & 5.7 & & \\
\hline \multicolumn{5}{|c|}{ HTC services prevents future infection } \\
\hline Strongly Agree & 115 & 35.6 & 3.09 & 1.14 \\
\hline Agree & 164 & 38.7 & & \\
\hline
\end{tabular}




\begin{tabular}{lllll}
\hline Variable & Freq & Percentage & $\overline{\mathbf{x}}$ & SD \\
\hline Disagree & 36 & 8.5 & \\
Strongly Disagree & 24 & 5.6 & \\
\hline
\end{tabular}

$\overline{\mathrm{x}}=$ mean, $\mathrm{SD}=$ Standard Deviation.

As shown in Table 2; most of the respondents believed the use of HTC service was likely to lower chances of HIV infection $(\overline{\mathrm{x}}=4.39 \mathrm{SD}=1.09)$. The standard deviation shows that they were unanimous in their responses. In relation to respondents believing that HIV positive persons who know their status were less likely to transmit the virus to someone else $(\overline{\mathrm{x}}=3.81 \mathrm{SD}=1.74)$, an indication that knowing ones status was likely to reduce transmission. Similarly, most of the respondents $(\overline{\mathrm{x}}=3.09 \mathrm{SD}=1.14)$ believed using the HTC service could help prevent getting HIV in future if found to be negative while there was less dispersion from the mean. This, from the analysis respondent's perceived benefit to HTC was confirmed $(\bar{x}=3.43)$. This is an indication that the majority of the respondents perceived there were benefits for using HTC services.

Table 3. Perceived Barriers.

\begin{tabular}{|c|c|c|c|c|}
\hline Variable & Freq. & Percentage & $\overline{\mathbf{x}}$ & SD \\
\hline \multicolumn{5}{|c|}{ Religious beliefs hindering HTC use } \\
\hline Strongly Agree & 39 & 9.2 & 2.41 & 0.66 \\
\hline Agree & 68 & 16.0 & & \\
\hline Don't Know & 87 & 20.5 & & \\
\hline Disagree & 121 & 28.5 & & \\
\hline Strongly Disagree & 109 & 25.7 & & \\
\hline \multicolumn{5}{|c|}{ High cost of HTC services } \\
\hline Strongly Agree & 46 & 10.8 & 2.44 & 0.96 \\
\hline Agree & 82 & 19.3 & & \\
\hline Don't Know & 149 & 35.1 & & \\
\hline Disagree & 94 & 22.2 & & \\
\hline Strongly Disagree & 52 & 12.2 & & \\
\hline \multicolumn{5}{|c|}{ Disclosure of HIV test results by staff } \\
\hline Strongly Agree & 54 & 12.7 & 2.12 & 0.61 \\
\hline Agree & 82 & 19.3 & & \\
\hline Don't Know & 115 & 27.1 & & \\
\hline Disagree & 104 & 24.5 & & \\
\hline Strongly Disagree & 69 & 10.2 & & \\
\hline \multicolumn{5}{|c|}{ People found at HTC assumed HIV positive } \\
\hline Strongly Agree & 90 & 21.2 & 2.58 & 0.31 \\
\hline Agree & 168 & 39.6 & & \\
\hline Don't Know & 33 & 7.8 & & \\
\hline Disagree & 87 & 20.7 & & \\
\hline Strongly Disagree & 46 & 10.6 & & \\
\hline
\end{tabular}

$\overline{\mathrm{X}}=$ mean, $\mathrm{SD}=$ Standard Deviation.

Table 3, depicts the analysis of the responses regarding perceived barriers to HIV Testing and Counselling. The respondents were indifferent $(\overline{\mathrm{x}}=2.41 \mathrm{SD}=0.66)$ as they did not perceive religious beliefs hinder their going for HTC clustering around the mean. They also did not agree that cost related to HTC services, prevent people from engaging in HIV testing and counselling $(\overline{\mathrm{x}}=2.44 \mathrm{SD}=1.96)$. On the issue of disclosure, the respondents were indifferent $(\overline{\mathrm{x}}=2.21$ $\mathrm{SD}=0.61$ ). they believed health staff at the HTC Centre might disclose results while most people were ambivalent on the perception that people might assume they are HIV positive if found going to the HTC centre $(\overline{\mathrm{x}}=2.58 \mathrm{SD}=0.31)$. Generally, the mean of the respondent's perceived barriers to HTC was indifferent $(\overline{\mathrm{x}}=2.41)$. This is an indication that majority of the respondents had low perception on barriers to HTC. Another area in the HBM considered was cues to action to HTC activities as indicated in Table 4.

Table 4. Cues to Action.

\begin{tabular}{|c|c|c|c|c|}
\hline Variable & Freq. & Percentage & $\overline{\mathbf{x}}$ & SD \\
\hline \multicolumn{5}{|c|}{ Often hear about HTC through family and friends } \\
\hline Strongly Agree & 70 & 16.5 & 3.11 & 1.26 \\
\hline Agree & 101 & 23.8 & & \\
\hline Disagree & 95 & 22.4 & & \\
\hline Strongly Disagree & 68 & 16.0 & & \\
\hline \multicolumn{5}{|c|}{ Knows someone who ever experience HTC } \\
\hline Agree & 94 & 22.2 & & \\
\hline
\end{tabular}




\begin{tabular}{lllll}
\hline Variable & Freq. & Percentage & $\overline{\mathbf{x}}$ & SD \\
\hline Don't Know & 89 & 21.0 & \\
Disagree & 123 & 29.0 & \\
Strongly Disagree & 77 & 18.2 & \\
\hline
\end{tabular}

$\overline{\mathrm{x}}=$ mean, $\mathrm{SD}=$ Standard Deviation.

The results in Table 4; shows that most of the respondents agreed $(\overline{\mathrm{x}}=3.11 \mathrm{SD}=1.26)$ hearing about HTC through friends and family with standard deviation showing homogeneity. The responses from the respondents less dispersed from the mean. In relation to respondents knowing someone who has ever experienced HTC, the results shows that most of the respondents $(\overline{\mathrm{x}}=3.91 \mathrm{SD}=1.14)$ affirmed knowing someone who had used HTC before. This provides evidence of the knowledge level of respondents and information flow. Thus, the level of awareness was high in the District among the youth. The general mean of 3.01 confirm the level of awareness of individuals having gone through HTC services in the District. The second part of the last objective shows the bivariate relationship between the demographic variables and the construct of the health belief model. The result is depicted in Table 5.

Table 5. Shows the Bivariate Relationship between the Demographic Variables and the Construct of the Health Belief Model.

\begin{tabular}{lllll}
\hline Correlation & Sex & Age & Place of Residence & Religion \\
\hline Sex & 1 & & & \\
Age & 0.0554 & 1 & & \\
Place of Residence & -0.1044 & -0.0679 & 1 & 1 \\
Religion & 0.0014 & 0.1107 & 0.0214 & -0.1092 \\
Level of Education & -0.0038 & -0.0713 & 0.1801 & 0.0457 \\
Marital Status & 0.0625 & 0.1707 & -0.235 & 0.0862 \\
Living Arrangement & 0.0884 & 0.2262 & -0.0914 & -0.0389 \\
Perceived Susceptibility & $0.1798^{*}$ & 0.0636 & -0.0288 & -0.0302 \\
Perceived Benefits & $-0.1093^{*}$ & 0.0393 & -0.0916 & -0.0761 \\
Perceived Barriers & -0.0058 & 0.0957 & 0.0972 & $0.1687^{*}$ \\
\hline
\end{tabular}

Table 5. Continued.

\begin{tabular}{|c|c|c|c|c|c|}
\hline Correlation & Marital Status & Living Arrangement & Perceived Susceptibility & Perceived Benefits & Perceived Barriers \\
\hline \multicolumn{6}{|l|}{ Sex } \\
\hline \multicolumn{6}{|l|}{ Age } \\
\hline \multicolumn{6}{|l|}{ Place of Residence } \\
\hline \multicolumn{6}{|l|}{ Religion } \\
\hline \multicolumn{6}{|l|}{ Level of Education } \\
\hline Marital Status & 1 & & & & \\
\hline Living Arrangement & 0.2505 & 1 & & & \\
\hline Perceived Benefits & -0.0891 & -0.0967 & 0.0408 & 1 & \\
\hline Perceived Barriers & $-0.1202 *$ & -0.0709 & 0.0699 & $0.1011 *$ & 1 \\
\hline
\end{tabular}

From 5; presents the bivariate relationship between the demographic variables and the constructs of the Health Belief Model. The results from this analysis suggest six correlated relationships although, they are marginal or weak. Firstly, perceived susceptibility correlated significantly with sex of respondent. Secondly, perceived benefits correlated significantly with sex. Thirdly, perceived susceptibility correlated with level of education. Fourthly, perceived benefits correlated with level of education. Fifthly, perceived barriers correlated with marital status. Lastly, perceived barriers correlated with perceived benefits. As expected, an increase in an individual's perceived benefits it likely to affect one's perceived barriers to the utilization of HTC services. In conclusion, the very weak correlation among the independent variables indicates little or no multicollinearity. Hence the independent variable can perfectly be used to predict the level of HIV Testing and Counselling in the study area.

\section{Discussion}

The objective of the study was to determine how some of the constructs of the health Belief model specifically perceived susceptibility, perceived barriers perceived benefits and cues to action relate to HTC participation. Results from the study shows that only a high number of the respondents (25\%) perceived susceptibility to HIV testing and counseling. In other words, perceived susceptibility was found to be significantly related to HTC. The results raised critical issues about motivation for HIV testing. Generally human beings, regardless of their status in the society need some form of motivation to change a particular behavioural pattern. The study discovered that the respondents perceived their susceptibility to HIV infection as high. This could be that most of the respondents had low level of motivation for HIV testing. This could explain why some of the respondents went for HTC, meaning that respondents 
who went for HTC perceived themselves to be at risk to HIV and AIDS and therefore their vulnerability to the epidemic might have determined their decision to get find out their HIV status.

In terms of other constructs of the model such as perceived barriers and perceived benefit as the study revealed, perceived barriers had no impact on HTC among the youth in the district, meaning it was insignificant to the uptake of HTC. This explains that the few respondents who went for HTC could have done so not because of any barriers associated to HTC but on other factors. On the other hand, he study revealed that perceived benefit and cues to action were highly associated to HTC participation. The implication is that other factors could have influenced the respondents' decision to uptake HTC. The finding is rather counter-intuitive because according to the tenets of health belief model, human beings would change their behavior in view of perceived or anticipated benefits or barriers associated with the behavior in context. However this finding is contrary to a study carried out in Addis Ababa in Ethiopia among students [20] where perceived barriers and perceived benefits were found to be closely associated with HTC, while over half of the respondents were found not to be susceptible.

Apart from the construct of the health belief model, some other demographic factors were used to test their association with HTC. The demographic variables of the respondents in the study include sex, age, place of residence, educational level and religion. It was revealed that modifying factors such as sex, age, and place of residence of respondents were found to be significant to the uptake of HTC. According to the results, the interactional effect of the demographic variables influenced the attitudes and beliefs of the respondents' towards HIV and AIDS in terms of decision to seek HIV testing and counselling services at health facilities. However, factors such as religion, level of formal education were found to be insignificant to HTC, contrary to the findings in Southern Ethiopia [21], which found that religion, educational level were significantly associated to HIV testing and counselling utilization among youth.

\section{Conclusion}

In sum, the impact of HIV and AIDS on the infected (the individual), society, health care system and the country as a whole is too frightening for any person to contemplate. In the advent of antiretroviral therapy, the sure way to bring the AIDS menace under control to ensure that all infected persons are identified and given the necessary care and support through HIV testing and counselling. Psychological and other personal factors have been identified in the literature as having hindrance on the uptake of HTC services among the youth. These are fear for being HIV positive, stigmatization or public labeling, discrimination, financial cost of HTC services, quality of counselling service, ignorance, lack of trust for workers at
HTC centre, age of the individual, marital status, religious affiliation, place of residence, occupation and level of education of the person and inadequate motivation. These Perceived barriers may either result in utilization or nonutilization of HTC services.

\section{Competing Interest}

The author declares no competing interest with respect to the research.

\section{Funding}

This research did not receive any specific grant from any funding agency in public, commercial or not for profit sectors.

\section{Acknowledgements}

Special thanks to the youth who participated in the study, Dr. Christian Aduamah and the entire staff of Fanteakwa District Health Directorate for the guidance.

\section{References}

[1] Barnett T, Whiteside A. AIDS in the twenty-first century: Disease and globalization. Springer; 2002 Jun 6.210-236.

[2] United Nations Agency for International Development (UNAIDS), Global EpidemicReport on HIV/AID update, Geneva. 2018.

[3] National AIDS/STI Control Programme,. Behavioural surveillance survey. Ghana AIDS Commission, Accra. 2017.

[4] Ghana AIDS Commission (GAC). HIV sentinels survey report and National prevalence. AIDS estimates report. Accra. 2017.

[5] Agyei-Mensah S, Aikins AD. Epidemiological transition and the double burden of disease in Accra, Ghana. Journal of urban health. 2010 Sep 1; 87(5):879-97.

[6] Mayosi BM, Benatar SR. Health and health care in South Africa-20 years after Mandela. New England Journal of Medicine. 2014 Oct 2;371(14):1344-53.

[7] Park BJ, Wannemuehler KA, Marston BJ, Govender N, Pappas PG, Chiller TM. Estimation of the current global burden of cryptococcal meningitis among persons living with HIV/AIDS. 2009 Feb 20; 23 (4), 525-30.

[8] Andoh-Robertson T, Ofori KN. HIV Testing and Counselling among the Youth of Ghana: The case of Tarkwa-Nsuaem and Fanteakwa District. Advances in Social Sciences Research Journal, 2018; 5 (9), 199-213.

[9] Kabiri MU. Factors Influencing Uptake of Hiv Testing and Counselling Among the Youth in Kintampo South District (Doctoral dissertation, University of Ghana)

[10] Christ-Koka E. Factors affecting HIV counselling and testing among students in the Ho Municipality. MSc Dissertation: University of Ghana. 2012. Retrieved 12/04/2016from http://dl,handle.net/12345 
[11] Farouq U, Ayiworoh A. An Exploratory Case Study of HIV/AIDS Related Stigma in Rural Ghana Thesis presented to The University of Guelph Guelph, Ontario, Canada retrieved on April, 2016 from

https://atrium.lib.uoguelph.ca/xmlui/bitstream/handle/10214/96 91 .

[12] Moodi M, Mood MB, Sharifirad GR, Shahnazi H, Sharifzadeh G. Evaluation of breast self-examination program using Health Belief Model in female students. J Res Med Sci. 2011;16 (3):316-22.

[13] Rosenstock, Irwin. Historical Origins of the Health Belief Model. New Jersey: Charles B. Slack, Inc. 1974.

[14] Ebadifard FRS, Rahmati F. Effects ofTraining Breast-Cancer Screening on Female University Students' Beliefs [in Persian]. Iran J Obstetrics, Gynecology \& Infertility. 2012; 15 (23):10 7.

[15] Teitler-Regev S, Shahrabani S, Benzion U. Factors affecting intention among students be vaccinated against $\mathrm{A} / \mathrm{H} 1 \mathrm{~N} 1$ influenza: to a health belief model approach. Advances in preventive medicine. 2011; 2011.

[16] Macintyre K, Rutenberg N, Brown L, Karim A. Understanding perceptions of HIV risk among adolescents in KwaZulu-Natal. AIDS and Behavior. 2004 Sep 1;8(3):237-50.

[17] Mathingau FA. Factors influencing acceptance of routine HIV Testing and Counseling Among pregnant women in Kibera informal settlement, Nairobi, Kenya (masters dissertation, kenyatta university) https://scholar.google.com.

[18] Ajuwon AJ, Olaleye A, Faromoju B, Ladipo O. Sexual behavior and experience of Sexual coercion among secondary school Students in three states in North Eastern Nigeria. BMC public health. 2006 Dec; 6 (1):310.
[19] Crissman HP, Adanu RM, Harlow SD. Women's sexual empowerment and Contraceptive use in Ghana. Studies in family planning. 2012 Sep;43(3):201-12.

[20] Abede A, Mitikie G. Perception of High School Students towards Voluntary HIVCounselling and Testing, using Health Belief Model in Butajira, Ethiopian Journal of Health Development, 2010, 2 (11).

[21] Hirus BM. (2014). Factors influencing HIV Voluntary Counselling and Testing (VCT) Service utilization among Youth of Hawassa town: a Health Belief Model Approach, Southern Ethiopia. Journal of Science and Development, 2 (1), 49-58.

[22] Becker MH. The Health Belief Model and Personal Health Behavior. Journal of Health Education Monographs, 1974, 2 (4), 324-508.

[23] Downing-Matibag TM, Geisinger B. Hooking up and Sexual Taking Among College Students: A Health Belief Model Perspective, 2009, SAGE.

[24] Baum K. Adolescents and AIDS. 1997, Retrieved from www.kidsource.com. on15/5/2016.

[25] Rosenstock IM. Why People Use Health Services. The Milbank Memorial Fund Quarterly, 1966, 44(3), 94-127. Retrieved: April 12, 2017 from http://doi.org/10.2307/3348967.

[26] Kinnear PR, Gra CD. (2004). SPSS mode Sample, Hove, Psychology press. London.

[27] Ghana Statistical Service (GSS), (2014). 2010 Ghana Population Census Report. Accra: GSS. 